\title{
Understanding ice-sheet mass balance: progress in satellite altimetry and gravimetry
}

\author{
H.D. PRITCHARD, ${ }^{1}$ S.B. LUTHCKE, ${ }^{2}$ A.H. FLEMING ${ }^{1}$ \\ ${ }^{1}$ British Antarctic Survey, Natural Environment Research Council, Madingley Road, Cambridge CB3 OET, UK \\ E-mail: hprit@bas.ac.uk \\ ${ }^{2}$ Planetary Geodynamics Laboratory, NASA Goddard Space Flight Center, Code 698, Greenbelt, Maryland 20771, USA
}

\begin{abstract}
Satellite remote sensing has come to dominate the measurement of glacier and ice-sheet change. Three independent methods now exist for assessing ice-sheet mass balance and we focus on progress in two: satellite altimetry (ICESat) and gravimetry (GRACE). With improved spatial and temporal sampling, and synergy with ice flow measurements, both the mechanisms and causes changing mass balance can be investigated. We present examples of mass losses due to widespread, intensifying glacier dynamic thinning in northwest Greenland, but local ablation rates in the northeast that are unchanged for decades. Advances in GRACE processing reveal Greenland net ice-sheet mass loss continuing into 2010, at $195 \pm 30 \mathrm{Gta}^{-1}$. A similarly negative trend in the Gulf of Alaska has significant spatial and temporal variation, that highlights the importance of intense summer melting here. Strong summer melt on the Antarctic Peninsula also precipitated recent ice-shelf collapse and prompted rapid dynamic thinning of tributary glaciers at up to $70 \mathrm{~m} \mathrm{a}^{-1}$. Thinning continued for years to decades after collapse and propagated far inland. While understanding of the physical mechanisms of change continues to improve, estimates of future behaviour, and in particular the near-future glacial sea-level contribution, still rely on projections from such observations. We introduce the suite of new sensors that will monitor the ice sheets into the future.
\end{abstract}

\section{INTRODUCTION}

The entire history of satellite remote sensing falls since the founding of the International Glaciological Society (IGS) and the first issue of the Journal of Glaciology, but only in the past 20 years or so have satellites been able to reveal changes in glaciers and ice sheets. Another IGS milestone, its 50th anniversary in 1987, was celebrated by a special issue of the Journal of Glaciology that recognized the potential for remote sensing with a front cover showing an artist's impression of a planned Earth observation satellite and a review of the technology. The latter described early studies with visible data from a Landsat satellite, thermal imaging from National Oceanic and Atmospheric Administration-7 (NOAA-7), passive microwave measurements from Nimbus-5, synthetic aperture radar (SAR) from Seasat, photographs from Skylab and radar altimetry data from Geodetic and Earth Orbiting Satellite-3 (GEOS-3), Seasat and Geosat. These observations were used to map glacier margins, velocities, flowlines, facies, ice divides and icesheet topography (Zwally, 1987). With immature technology, a short archive of data and large, uncharted glacial landscapes, the first achievements were in mapping: creating inventories of ice and revealing patterns in surface features (e.g. US National Snow and Ice Data Center, http:// nsidc.org/dataGO1130.html). These achievements now stand as benchmarks against which we can measure change.

In recent years, satellite remote sensing for glaciology has focused on assessing glacier and ice-sheet mass balance. Three main methods have been employed: (1) measuring volume change with repeated altimetry and converting this to mass (using estimates of the density of snow or ice lost or gained), (2) measuring mass change directly with repeated gravimetry, and (3) calculating flux imbalance using measurements of glacier flow and knowledge of glacier thickness and surface mass balance (SMB). Significant progress has been made in techniques for measuring glacier flow, and hence the calculation of flux imbalance in method 3, but these are discussed in detail elsewhere in this issue. Here we focus on the techniques central to methods 1 and 2: the application of repeated satellite altimetry and gravimetry for glaciology. We consider the synthesis of these and complementary remotely sensed and other datasets that allow us to go from simply measuring change to investigating its causes and mechanisms. We present new studies from the Gulf of Alaska (GoA), the Antarctic Peninsula and the Greenland ice sheet (GIS) that use data from Ice, Cloud and land Elevation Satellite (ICESat) and Gravity Recovery and Climate Experiment (GRACE) satellite sensors to study rates and patterns of ice loss. We investigate the short- and longerterm response of tributary glaciers to ice-shelf collapse, estimate ablation rates of a stagnant ice-sheet margin, map the evolving pattern of dynamic thinning on outlet glaciers and reconcile high-resolution measurements of changing gravity fields to show both seasonal and interannual net mass balance over large areas. We conclude by previewing forthcoming sensors relevant to studies of the cryosphere.

\section{SATELLITE ALTIMETRY FOR GLACIOLOGY}

The surface height of $>70 \%$ of the Antarctic ice sheet (AIS) and almost all of the GIS has been measured continuously by several radar satellite missions since the commissioning of the first European Remote-sensing Satellite (ERS-1) in 1992 (Wingham and others, 2006, 2009; Thomas and others, 2008). These measurements have revealed areas of rapid thinning, particularly in coastal West Antarctica, attributed primarily to ice loss due to glacier acceleration (Shepherd and others, 2002), and large areas of slight thickening in the ice-sheet interiors attributed largely to changes in accumulation (Helsen and others, 2008). This archive of data has 


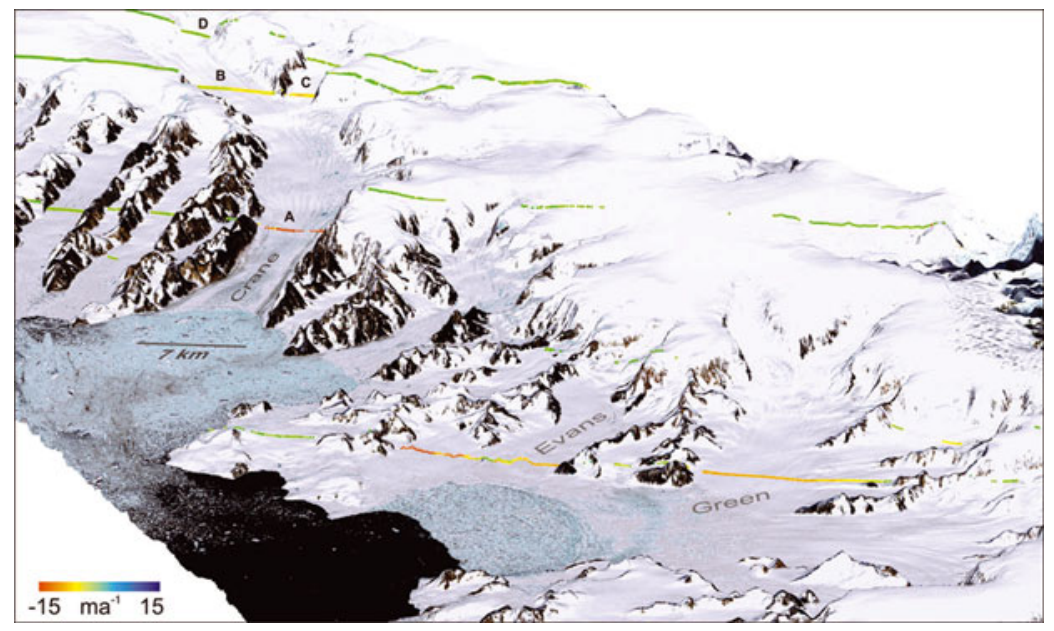

Fig. 1. A perspective view of Evans, Green and Crane glaciers, Antarctic Peninsula, thinning dynamically after the collapse of the Larsen B ice shelf. Coloured tracks show the rate of surface height change from ICESat, draped over an elevation model and images from the highresolution Système Probatoire pour I'Observation de la Terre (SPOT) satellite sensor (SPOT 5 stereoscopic survey of Polar Ice: Reference Images and Topographies (SPIRIT) project). Only the main glacier trunks - the fast-flowing ice - are thinning. A, B, C and D refer to time series in Figure 2.

provided an unprecedented view of ice-sheet volume change but is not well suited to the most rapidly changing areas near the margins of outlet glaciers, being limited to shallow slopes $\left(\sim 1^{\circ}\right)$, and having relatively low resolution $(2-3 \mathrm{~km}$ footprints) and low measurement density (at orbit crossovers). Also, radar surface penetration can vary through time, introducing spurious height-change signals (Thomas and others, 2008). However, the largest source of error in converting volume change measurements to mass changes (a problem common to all altimeter systems) is in assigning a density to the snow or ice lost or gained (Wingham and others, 2006). Changes in the firn density profile driven by a departure from the long-term mean SMB or densification rate generate volume changes at a variable and imperfectly known density, whereas changes in flow rate drive volume changes at the known density of ice. Separating these firn and ice signals when measuring volume change is, however, problematic. As a consequence, large uncertainties in icesheet mass balance from altimetry arise from uncertainties in modelled ice-sheet SMB (which for Greenland is $~ 9 \%$ precision or $41 \mathrm{Gta}^{-1}$ (Ettema and others, 2009)) and from problems in modelling snow compaction, particularly the role of snowmelt in surface height change.

A spaceborne laser altimeter, ICESat, was launched in 2003. Able to resolve narrow, steep outlet glaciers (with a footprint of $65 \mathrm{~m}$ and along-track spacing of $172 \mathrm{~m}$ ), with minimal surface penetration and orbiting to a higher latitude, it was designed to overcome some of the limitations of radar altimetry. Technical issues, however, reduced the number of repeated tracks (Abshire and others, 2005), and tracks were rarely repeated precisely, usually being offset by up to a few hundred metres. Except at relatively sparse track crossovers, this has made height-change measurement from these data difficult without knowledge of the cross-track slope (Scambos and others, 2004). To make use of the dense along-track data between the crossovers, Pritchard and others (2009) developed an interpolation-comparison scheme that achieved much greater coverage of surface height changerate $(\mathrm{d} H / \mathrm{d} t)$ measurements with an acceptable uncertainty $\left( \pm 0.07 \mathrm{~m} \mathrm{a}^{-1}\right.$ where spatially averaged). The great advantage arising from dense along-track sampling of change was the ability to measure height change on adjacent fast- and slowflowing ice (identified from SAR interferometry (InSAR)) products in the same climatic setting on the ice-sheet margins. Differences in height change between these surfaces result from flow dynamics, not changes in SMB or firn density. This made it possible to attribute height changes to a particular cause without requiring knowledge of the long-term average and short-term deviations in climate, and hence allowed the distribution of dynamic thinning due to glacier acceleration to be mapped over the full extent of the ice-sheet coasts. We use this same technique to exploit highresolution ICESat data in the following studies of glaciers on the Antarctic Peninsula and coastal Greenland.

\subsection{Ice loss following the collapse of ice shelves on the Antarctic Peninsula}

The response of tributary glaciers to ice-shelf collapse is important because $>80 \%$ of Antarctic ice drains through ice shelves (Riffenburgh, 2006) which are vulnerable to collapse in a warming environment, being susceptible to melt from above in warm summer weather, and from below by incursions of warm water. They can collapse suddenly if 'bridging' stresses that hold the shelf together become compromised by progressive frontal retreat (Doake and others, 1998) or failure by hydrofracture (Scambos and others, 2009). The collapse in January 1995 of the Larsen A ice shelf and in January-March 2002 of Larsen B followed intense surface melting, and a punctuated retreat of the fronts revealed by the archive of passive-microwave, visible and SAR satellite data (Scambos and others, 2000, 2003). The collapse initially triggered a rapid and substantial acceleration response from their tributary glaciers which was measured separately using InSAR and Landsat feature tracking (Rott and others, 2002; Rignot and others, 2004; Scambos and others, 2004). These observations conclusively demonstrated that ice shelves can act to buttress glacier flow, which is highly sensitive to perturbations at the marine margin.

The question remained as to whether this response would be transient and localized to the lower glacier or would be sustained and would spread up-glacier. Figures 1 and 2 show how glacier surface height changed in the years following the 

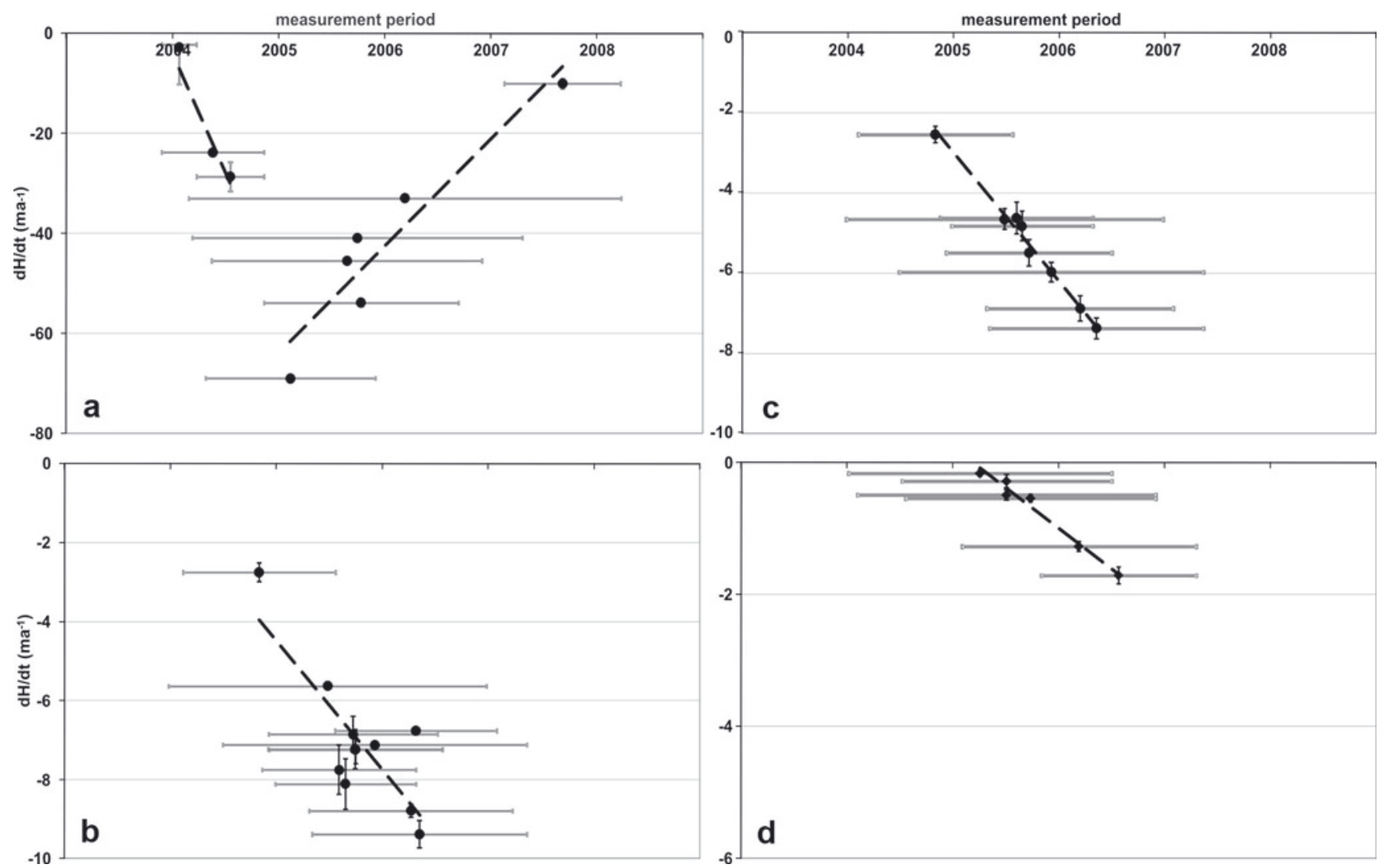

Fig. 2. Rates of surface-height change on Crane Glacier through time. Horizontal bars show the period covered by each measurement. Vertical bars show measurement uncertainty. (a) Rapid acceleration of thinning following the collapse of the Larsen B ice shelf, peaking at $\sim 70 \mathrm{~m} \mathrm{a}^{-1}$ before falling linearly to $\sim 10 \mathrm{~m} \mathrm{a}^{-1}$ in 2007/08 (some error bars not visible at this scale). (b, c) The thinning signal arrived later and was attenuated in mid-glacier. (d) Slight thinning is apparent in the upper glacier. (Note change in scale on $y$-axes.) Location of sites marked in Figure 1.

collapse, from along-track comparisons of ICESat laser altimeter data (after Pritchard and others, 2009). Strong thinning was confined to the fast-flowing main trunks of Evans, Green and Crane glaciers while the slow-flowing ice at the coast and higher up on the plateau remained unchanged (Fig. 1). This is diagnostic of dynamic thinning driven by glacier acceleration. Initial thinning was extremely rapid on the lower Crane Glacier (Fig. 2a), accelerating up to $70 \mathrm{~m} \mathrm{a}^{-1}$ after 3 years, but the thinning rate subsequently declined. Thinning arrived later in mid-glacier and rose steadily (Fig. 2b and c), and slight thinning is detectable even at $65 \mathrm{~km}$ inland of the 2002 glacier front (and at $1100 \mathrm{~m}$ altitude), 4-5 years after the collapse. This complements independent flow measurements from SAR feature tracking showing that Green and Hektoria Glaciers experienced an initial tenfold acceleration following ice-shelf collapse (1999-2004), that declined to a $20 \%$ acceleration for 2004-06 (Rott and others, 2007). These observations are qualitatively similar to modelled diffusive up-glacier propagation of dynamic thinning. They are consistent with initial acceleration due to strong gradients in longitudinal stress in the lower glacier after the loss of ice-shelf buttressing (and potentially decreased effective pressure as the margin goes afloat), followed by increased driving stress as the surface slope progressively steepens (Payne and others, 2004). In the case of Crane Glacier, thinning propagated at least as far inland as the plateau icefalls, and when we look to other cases of glaciers that have experienced ice-shelf collapse in this region (Sjögren, Drygalski and Fleming glaciers after the collapse of Prince Gustav, Larsen A and Wordie ice shelves), we see that thinning subsequently propagated either up to the glacier headwall (Fig. 3a and b) or into the interior of the icecap plateau at these sites too (Fig. 3c).

This combination of, flow, altimetry, extent and melt measurements from a variety of satellite sensors recording at electromagnetic frequencies from optical to microwave parts of the spectrum shows us that rapid ice-shelf collapse results from a combination of surface melt-ponding and frontal retreat. It causes abrupt and rapid acceleration and hence dynamic thinning of the lower reaches of tributary glaciers. We show that this declines over subsequent years, but the thinning signal continues to propagate diffusively far inland for years or decades until most or all of the glacier drainage basin has thinned and steepened as it tends towards a new equilibrium profile.

\subsection{Patterns and causes of glacier change in Greenland}

Shortly after Larsen B collapsed on the Antarctic Peninsula, satellite observations of coastal Greenland began to show similarly dramatic ice losses. Notably, up to a doubling in speed of the large outlet glaciers Helheim, Kangerdlugssuaq and Jakobshavn was observed with SAR and visible (Advanced Spaceborne Thermal Emission and Reflection Radiometer (ASTER)) image feature tracking, associated with rapid frontal retreat (Joughin and others, 2004; Howat and others, 2005; Luckman and others, 2006). Subsequent SAR studies showed widespread acceleration over the observation 


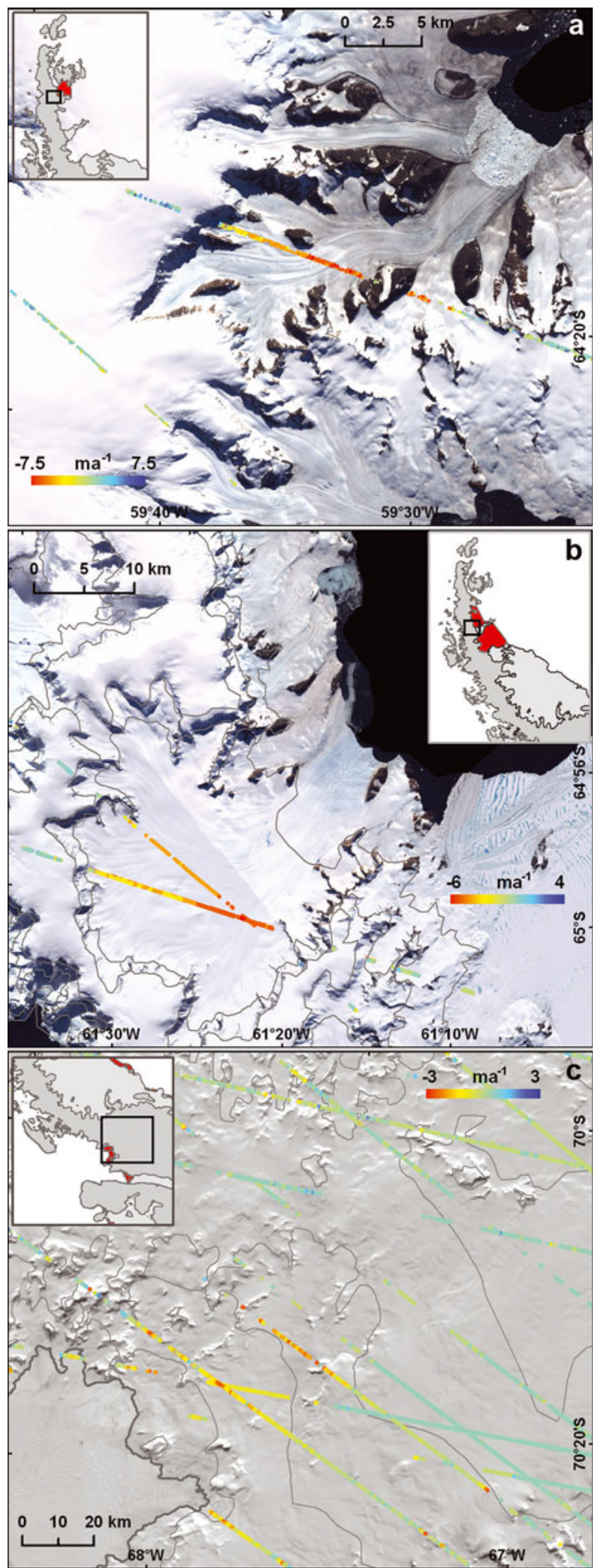

Fig. 3. Thinning of Antarctic Peninsula former ice-shelf tributaries after collapse, for the period 2003-08. (a) Sjögren Glacier following collapse of the Prince Gustav Ice Shelf in 1993 (inset: former shelf extent (1959) in red). (b) Drygalski Glacier following collapse of Larsen A ice shelf in 1995 (inset: former extent of Larsen A and B in red). (c) Fleming Glacier after the late-1980s collapse of the Wordie Ice Shelf (inset: former shelf extent in red). All three glaciers continue to thin strongly high up into their drainage basins. Contours are altitude (500 m intervals); background images are from the Landsat Image Mosaic of Antarctica (LIMA) (a, b) and the Moderate Resolution Imaging Spectroradiometer (MODIS) Mosaic of Antarctica (MOA) (c).

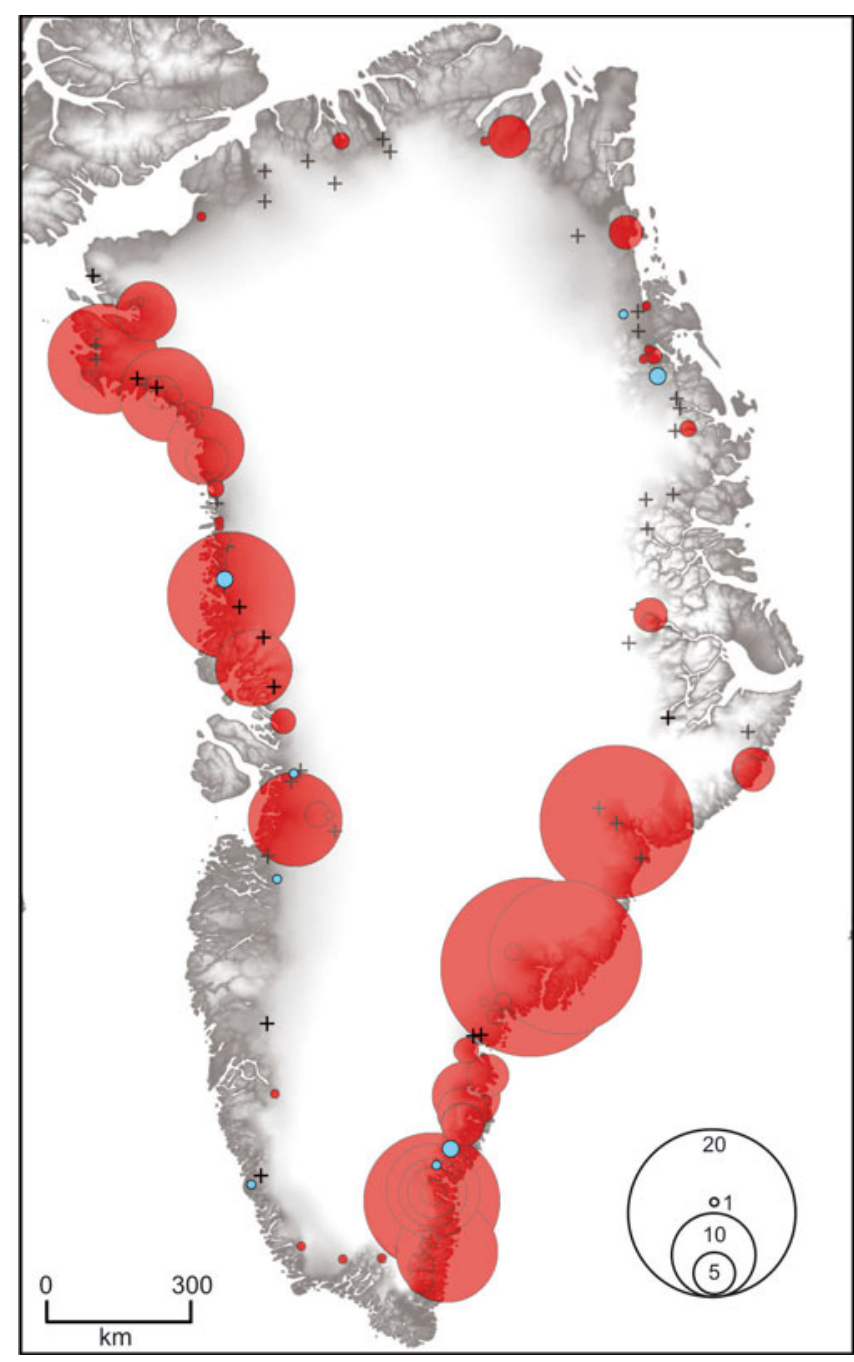

Fig. 4. The distribution and magnitude of dynamic thinning (red) and thickening (blue) in Greenland derived from ICESat laser altimetry (Pritchard and others, 2009). Circle diameter represents magnitude of change in $\mathrm{ma}^{-1}$. Crosses show studied glaciers that are unchanging. Measurements are maxima from the lower reaches of individual glaciers, where ICESat data are available.

period (Rignot and Kanagaratnam, 2006; Howat and others, 2008), but feature tracking with visible images showed flow rates to be highly variable through time. Digital elevation models made from ASTER-image stereo pairs demonstrated, however, that the surface elevation change signal smooths these high-frequency flux changes, hence the signal observed is less susceptible to measurement timing and more representative of the trend of ice loss through dynamic thinning (Howat and others, 2007).

ICESat laser altimeter measurements that resolve the narrow outlet glaciers of coastal Greenland confirmed the presence of acceleration-driven dynamic thinning, independently of flux calculations based on knowledge of flow rate and mass balance (Fig. 4). Ice loss is concentrated on the southeast and northwest coasts on many large, high-flux glaciers that reach the sea (in contrast to adjacent slowflowing ice), and the distribution of dynamic thinning agrees well with glaciers showing recent (1996-2006) acceleration and retreat (Rignot and Kanagaratnam, 2006; Joughin and others, 2010).

When we compare height-change rates for the early and later periods of the ICESat mission (Fig. 5), we see a pattern 


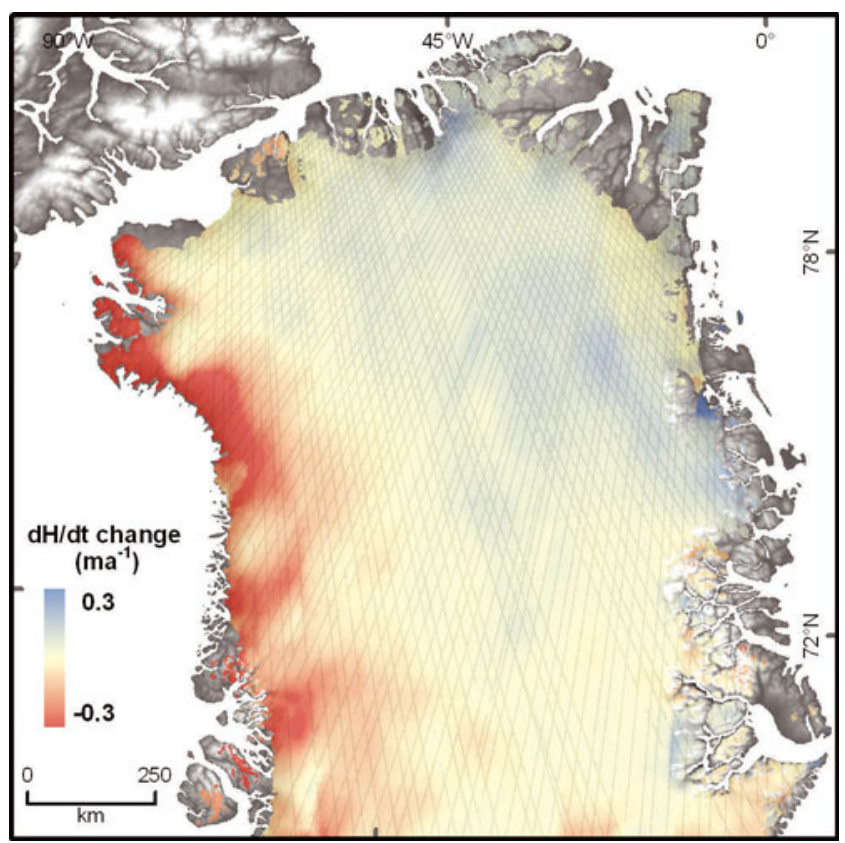

Fig. 5. Change in rate of $\mathrm{d} H / \mathrm{d} t$ for central and northern Greenland between early-period ICESat (2003/04 to 2005/06 (centred around April 2004 and October 2005 respectively)) and late-period ICESat (2004/05 to 2006/07 (centred around March 2005 and September 2006 respectively)). The average time interval $(\mathrm{d} t)$ for the two periods is 676 and 668 days. Gridding is $10 \mathrm{~km}$; averaging is over a $50 \mathrm{~km}$ radius. ICESat tracks are shown as grey lines.

of accelerated loss in the dynamically thinning northwest, predicted by Rignot and Kanagaratnam (2006) and suggesting intensified regional forcing of glacier flow. Holland and others (2008) showed that the spread of warm subsurface ocean waters from the south, driven by changing winds over the North Atlantic, was the probable cause of glacier acceleration on the west coast.

In certain cases, it is possible to use the same remotesensing tools to measure another key parameter in understanding glacier change, the local ablation rate. The surgetype glaciers Storstrømmen and L. Bistrup Bræ, northeast Greenland, are exceptions to the pattern of dynamic thinning (Fig. 6). These glaciers are distributaries of the 'Northeast Greenland Ice Stream', in quiescence following a surge from 1978 to 1984 (Reeh and others, 2002). Zones of (dynamic) thickening (blue tracks) and thinning (red tracks) from ICESat correspond closely to areas of emergent flow (green polygons) and stagnation (orange polygons) that were detected using InSAR (Reeh and others, 2003; Fig. 6). They demonstrate recharging of ice in the upper glacier while the stagnant termini (Rignot and others, 2001; Joughin and others, 2010) lower by ablation. This stagnant flow gives us the opportunity to use the ICESat surface height change to estimate directly the local ablation rate for the 2003-08 period (after Reeh and others, 2002). We find that ablation approached $-1.8 \pm 0.3$ mw.e. $\mathrm{a}^{-1}$ (from Fig. 7, using ice density $917 \mathrm{~kg} \mathrm{~m}^{-3}$ ). This is similar to the maximum rate measured between 1994 and 1999 using InSAR and airborne laser altimetry $\left(-1.6 \pm 0.2 \mathrm{~m} \mathrm{a}^{-1}\right)$, similar to 1989 92 field measurements $\left(-1.35 \mathrm{~m} \mathrm{a}^{-1}\right.$, and modelled as unchanged from 1949 to 1991) (Bøggild and others, 1994), 1993-94 field measurements $\left(-2 \mathrm{~m} \mathrm{a}^{-1}\right)$ (Reeh and others, 2002), and to the 1958-2007 modelled average

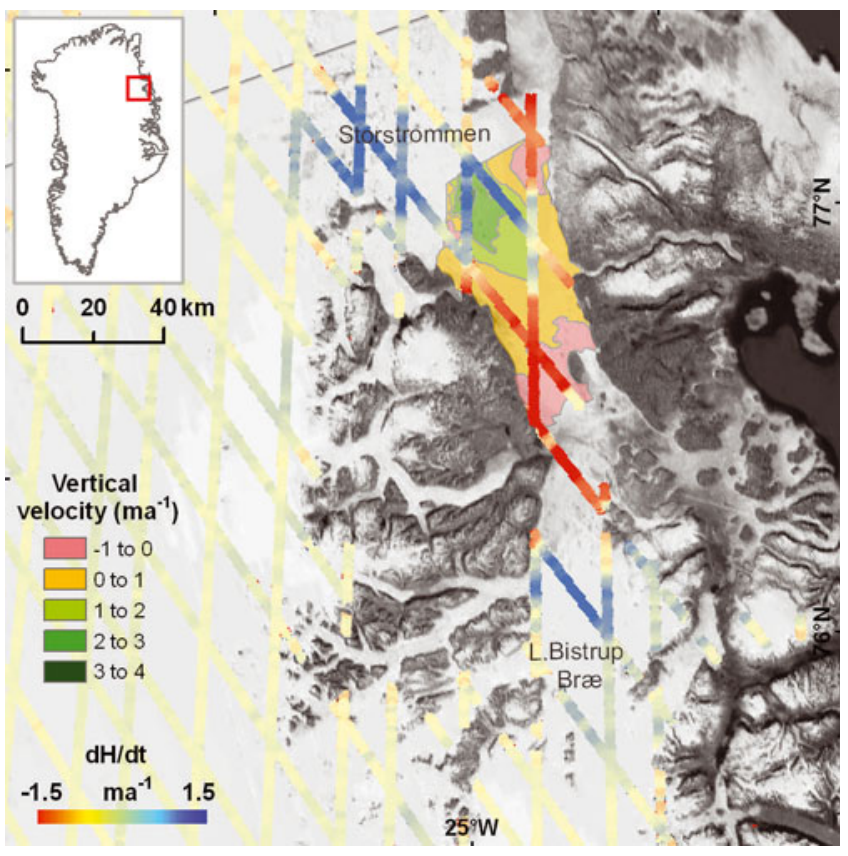

Fig. 6. Tracks of surface $\mathrm{d} H / \mathrm{d} t$ on Storstrømmen and L. Bistrup Bræ, northeast Greenland, from ICESat (2003-07) (coloured tracks, horizontal scale bar), superimposed on Storstrømmen emergence/ submergence velocities calculated from InSAR strain measurements (coloured polygons, vertical legend): a $25 \mathrm{~km}$ long zone of the stagnating lower glacier has an emergence/submergence velocity of $0 \pm 0.2 \mathrm{~m} \mathrm{a}^{-1}$ (Reeh and others, 2003).

( -1 to $-2 \mathrm{ma}^{-1}$ with a trend of $-0.01 \mathrm{ma}^{-1}$ ) (Ettema and others, 2009). These comparisons indicate little change in ablation in this area of coastal northeast Greenland.

\section{GRACE OBSERVATIONS OF LAND-ICE MASS EVOLUTION}

Radar and laser altimetry have revealed both detailed and broad patterns of volume change on the ice sheets, and, as described, it is sometimes possible to distinguish losses and gains of ice (with known density) from those of firn, where the conversion to a change in mass is more difficult.

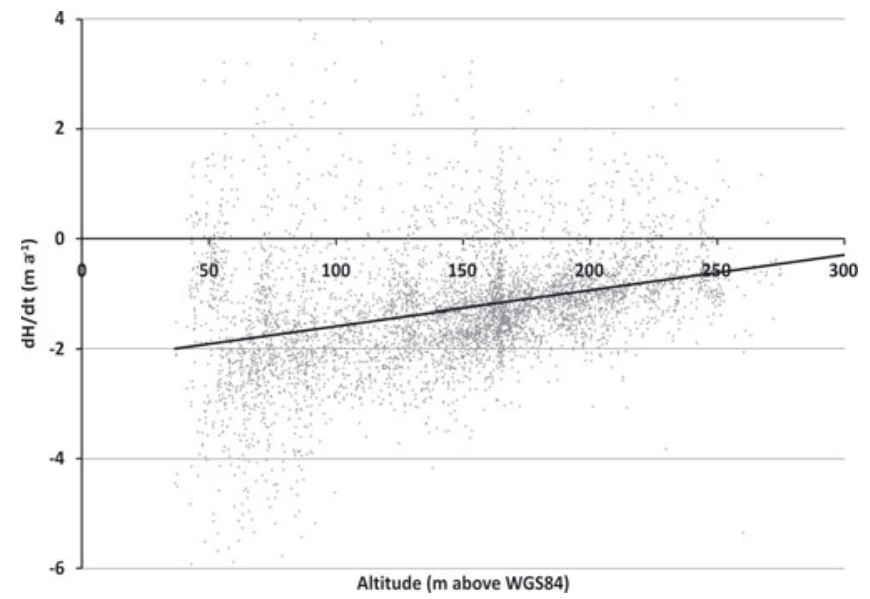

Fig. 7. Surface height change rate with altitude (2003-07) for stagnant ice in the ablation area of Storstrømmen. (WGS84: World Geodetic System 1984 ellipsoid.) 


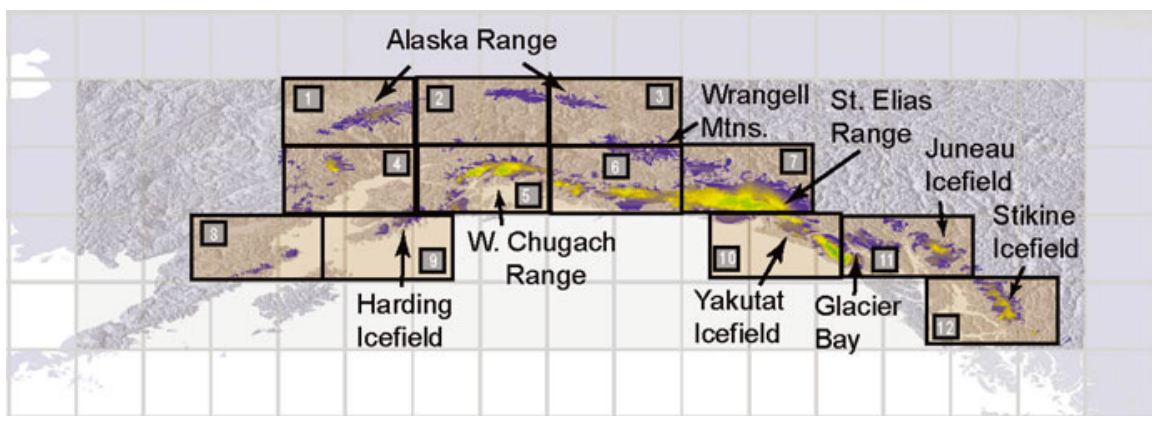

Fig. 8. Detail of glacier region mascons 1-12 (Arendt and others, 2008).

Measuring changes in mass (and hence sea-level contribution) with altimetry remains problematic for many areas, including the ice-sheet interiors. A novel and entirely different approach to quantifying mass change in glacial environments is to measure their time-varying gravity field by satellite. Here we introduce this technique, and we summarize two analyses that present both the capability and limitations of current satellite-based estimates of land ice evolution.

Since its launch in March 2002, the GRACE mission has acquired ultra-precise inter-satellite range and range-rate measurements taken between two co-orbiting satellites at $450 \mathrm{~km}$ altitude, $\sim 220 \mathrm{~km}$ apart (Tapley and others, 2004). Changes in the range and range-rate are used to estimate the changes of the Earth's geopotential due to solid-earth and surface and atmospheric mass-transport processes, including glacier accumulation and ablation (Rummel, 1980; Kahn and others, 1982; Gaposchkin, 2000; Rowlands and others, 2002). The GRACE project provides the time-variable gravity observations in the form of monthly sets of Stokes coefficients or spherical harmonic fields (Tapley and others, 2004; Reigber and others, 2005). These monthly fields are estimated from the reduction of the range-rate data with precise positioning, attitude and accelerometer data to isolate gravity forces from non-conservative surface forces acting on the GRACE satellites (Tapley and others, 2004; Reigber and others, 2005; Luthcke and others, 2006a).

As with ICESat altimetry, sampling issues must be addressed with GRACE data for glaciology applications. Limitations on the temporal and spatial sampling of GRACE complicate analysis of a changing gravity field because north-south striping artefacts arise from the limited longitudinal sampling of the GRACE orbits within monthly time periods (Swenson and Wahr, 2002; Velicogna and Wahr, 2005; Luthcke and others, 2006a; Wouters and others, 2008). Smoothing and regional-averaging filtering techniques have been used to estimate overall glacier mass balance for the GoA region, the GIS and the AIS from the GRACE monthly spherical harmonic fields (e.g. Tamisiea and others, 2005; Klees and others, 2008; Wouters and others, 2008), but many of the filtering methods are not optimal (they do not take into account the noise covariance of the estimated Stokes coefficients) (Klees and others, 2008). Loss of signal amplitude and limited spatial and temporal resolution, as well as signal leakage in and out of regions of interest, are particular problems when applying filtering methods.

An alternative technique to the filtering of the monthly Stokes coefficients to obtain surface mass change from GRACE data is the so-called 'mascon' technique. In this approach, the gravity contribution from surface parcels of equivalent water height (mascons) are estimated in consecutive time intervals (typically every 10 days), estimating the mass change directly from GRACE range-rate data (which accounts for the full Stokes noise covariance) (Rowlands and others, 2005, 2010; Luthcke and others, 2006b, 2008; Sabaka and others, 2010). The mascon technique has particular advantages over other filtering approaches in terms of spatial resolution and geolocating physical causes of change to the gravity field, as it facilitates the application of geolocatable physical constraints and uses consistent signal and noise covariance derived directly from GRACE inter-satellite ranging data.

In the following example, we first present a summary of the GoA glacier mass change from mascon solutions. This example is meant to demonstrate the temporal and spatial resolutions and accuracies that GRACE-based estimates of land ice evolution can achieve in a challenging region. In the second example, we present a comparison of GIS mass evolution derived from different techniques and fundamental GRACE processing to demonstrate the issues limiting solution precision and the capabilities of the technique for whole-ice-sheet mass-balance assessment.

\subsection{Glacier mass loss from the Gulf of Alaska}

Luthcke and others (2008) demonstrated that GRACE was capable of resolving surface mass variations at high temporal (10 day) and spatial ( $2^{\circ}$ equal-area mascon) resolution (Fig. 8), and that these resolutions were necessary to capture properly the GoA signal. The high-resolution mascon solutions reveal considerable temporal and spatial variation within the GoA glacier region, with the largest negative mass balances observed in the St Elias Mountains including the Yakutat and Glacier Bay regions (Fig. 9). The most rapid losses occurred during the 2004 melt season (Fig. 10; Table 1) due to record temperatures in Alaska during that year. This accounted for record negative balances of Gulkana and Black Rapids Glaciers as observed in their long in situ massbalance records (2008). The investigation marked the first comprehensive measurements of glacier seasonal and annual mass balances from GRACE (Table 1). Arendt and others (2008) investigated the validity of the GoA mascon solution trends for the St Elias region through a comparison with airborne laser altimetry obtained over the same time period as GRACE observations. Their results found a mass balance of $-21.2 \pm 3.8 \mathrm{Gta}^{-1}$ obtained from the laser altimetry and a mass balance of $-20.6 \pm 3.0 \mathrm{Gta}^{-1}$ from the GRACE highresolution mascon solutions. The results demonstrated the validity of the high-resolution mascon solutions to determine accurately the mass balance of regional glacier systems having large mass-change signals. 


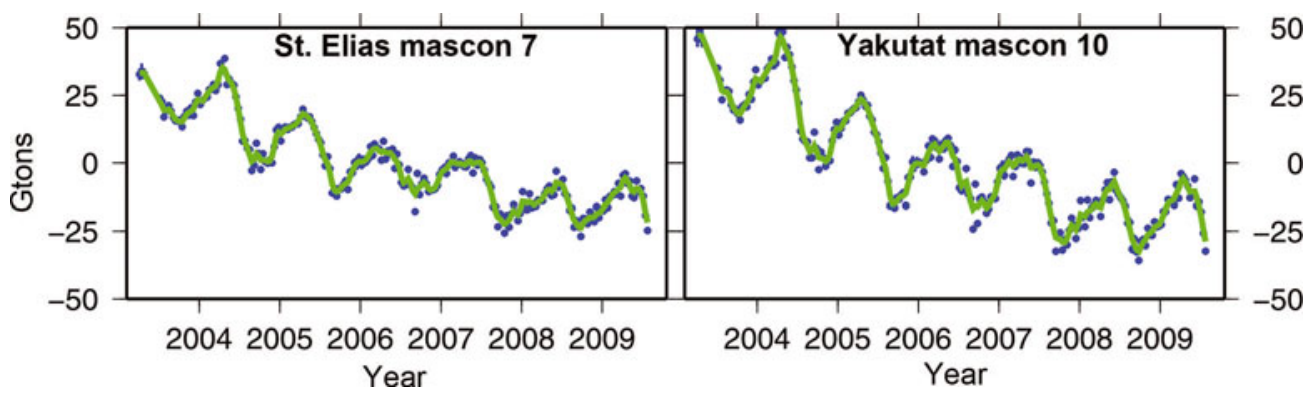

Fig. 9. GRACE-derived time series of mass from the St Elias mascon and the Yakutat mascon showing significant interannual mass loss and strong seasonal variability (blue dots: 10 day solutions with error bars; green line: 10 day Gaussian filter). (Update to Luthcke and others, 2008.)

\subsection{Glacier mass loss from Greenland}

A number of assessments of GIS mass balance have previously been made using GRACE data (e.g. Velicogna and Wahr, 2005; Luthcke and others, 2006b; Velicogna, 2009; Schrama and Wouters, 2011), but these assessments show discrepancies that require explanation. Here we present the mass-balance time series for the GIS processed using the high-resolution mascon techniques developed and validated in the GoA analysis. We can now compare this mascon time series (computed by summing the contributions for every GIS mascon) with that produced by filtering using a regional averaging-kernel technique with the GRACE-derived monthly spherical harmonic fields (as in Velicogna and Wahr, 2005; Luthcke and others, 2008) (Fig. 11; Table 2). This comparison demonstrates that when considering an area the size of the GIS (and using the same fundamental GRACE Level-1B data processing (GSFC v08)), the two techniques agree quite well within their estimated errors. However, we observe more significant differences in the GIS time series when we apply the same averaging kernel technique to the spherical harmonic time series distributed from the different GRACE processing centres (each centre uses a different Level-1B processing). The results indicate that the discrepancies in GRACE-derived GIS mass-balance estimates found in the literature (corrected for the time period the solutions are valid) are likely to be due, not to differences in technique (spherical harmonic filtering versus mascon solutions), but rather differences in fundamental GRACE Level-1B data processing (i.e. in the various

Table 1. Winter $\left(B_{\mathrm{W}}\right)$, summer $\left(B_{\mathrm{S}}\right)$ and net balances $(B)$ for the total GoA glacier mascon region between 2003 and 2009, determined as the difference between yearly maximum and minimum in the mascon time series (Fig. 3). Balance years begin in the fall of the previous calendar year. (Update to Luthcke and others, 2008)

\begin{tabular}{lllc}
\hline Balance year & $B_{\mathrm{W}}$ & $B_{\mathrm{S}}$ & $B$ \\
& $\mathrm{Gt}$ & $\mathrm{Gt}$ & $\mathrm{Gt}$ \\
& & & \\
2004 & $233 \pm 26$ & $-378 \pm 25$ & $-145 \pm 36$ \\
2005 & $232 \pm 9$ & $-299 \pm 5$ & $-66 \pm 11$ \\
2006 & $205 \pm 8$ & $-261 \pm 17$ & $-55 \pm 19$ \\
2007 & $224 \pm 17$ & $-278 \pm 11$ & $-54 \pm 20$ \\
2008 & $190 \pm 9$ & $-199 \pm 7$ & $-9 \pm 12$ \\
2009 & $208 \pm 12$ & & \\
Average & $215 \pm 17$ & $283 \pm 64$ & $-66 \pm 49$
\end{tabular}

processing centres' series of spherical harmonic fields). This source of error is likely to be reduced with improvements in GRACE fundamental data processing. However, for the time being, our estimate of the solution precision must be accounted for when considering the GRACE solutions for cryospheric mass balance.

The contributions from formal solution uncertainty, uncertainty in Glacial Isostatic Adjustment correction, uncertainty in forward modelling of atmospheric and ocean mass variations and our estimate of solution precision (Table 2) provide an estimate of the error in GRACEdetermined GIS mass-balance trend that is on the order of $\pm 30 \mathrm{Gt} \mathrm{a}^{-1}$. Therefore, from this analysis (Table 2) we obtain a GIS mass-balance trend of $-195 \pm 30 \mathrm{Gta}^{-1}$ for the period 1 August 2003 to 1 August 2009. This can be compared to estimates from the flux-balance approach (flow measurements and SMB modelling) of $-110 \pm 70 \mathrm{Gt} \mathrm{a}^{-1}$ for the $1960 \mathrm{~s}$, $-30 \pm 50 \mathrm{Gt} \mathrm{a}^{-1}$ for the $1970 \mathrm{~s}-80 \mathrm{~s},-97 \pm 47 \mathrm{Gt} \mathrm{a}^{-1}$ for 1996 (Rignot and others, 2008), $-138 \pm 31 \mathrm{Gta}^{-1}$ for 2000, $-224 \pm 41 \mathrm{Gt} \mathrm{a}^{-1}$ for 2005 (Rignot and Kanagaratnam, 2006) and $-267 \pm 38 \mathrm{Gt} \mathrm{a}^{-1}$ for 2007 (Rignot and others, 2008).

\section{NEW AND FORTHCOMING SENSORS FOR GLACIER AND ICE-SHEET CHANGE DETECTION}

In addition to the current flotilla of satellites already in orbit which are used to monitor glaciers and ice sheets, we can look forward to increased use of these techniques thanks to an abundance of new and planned platforms in the years ahead (Fig. 12). Sensors currently used for monitoring changes in ice extent, height and velocity are all set to be

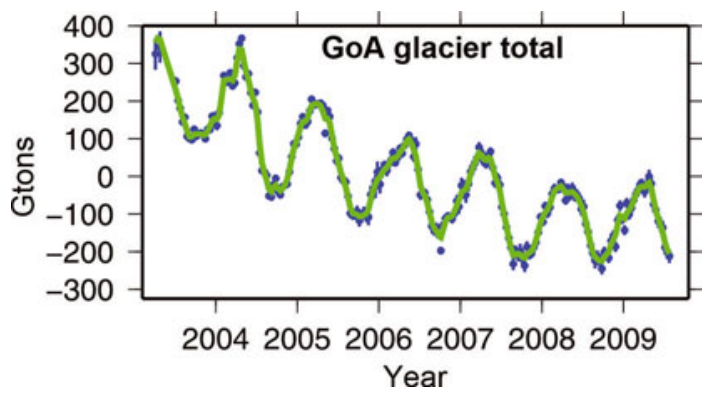

Fig. 10. Total GoA glacier mascon solution time series computed from the sum of mascons 1-12. The largest losses are observed during the 2004 melt season (blue dots: 10 day solutions with error bars; green line: 10 day Gaussian filter). (Update to Luthcke and others, 2008.) 


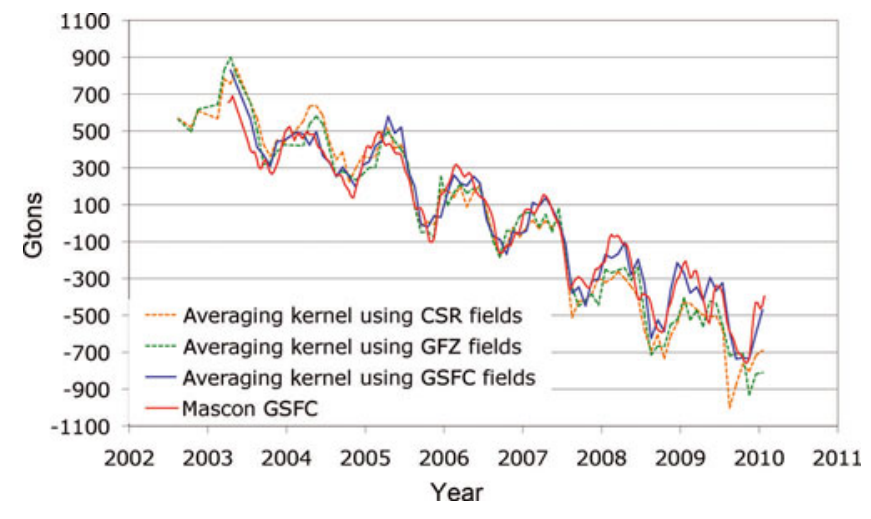

Fig. 11. GIS mass time series; comparing techniques (mascon versus averaging kernel) and Level-1B data processing represented by different processing centres: Center for Space Research (CSR), GeoForschungZentrum (GFZ) and Goddard Space Flight Center (GSFC).

continued and enhanced thanks to new missions with better resolution, more frequent observations and improved measurements.

Radar altimetry provides one of the longest observation records of ice-sheet elevation, and the recent successful launch of CryoSat-2 (http://www.esa.int/esaLP/LPcryosat.html) means a great improvement in these observations since it addresses many of the limitations of polar monitoring with previous systems which were primarily targeted at the oceans. Firstly, it will minimize important gaps in coverage by providing observations closer to the poles than previous altimeters due to a higher-incidence-angle orbit $\left(92^{\circ}\right)$. Secondly, it will provide much-improved elevation data on the more steeply sloping surfaces at the ice-sheet margins where previous radar altimeters perform poorly. The CryoSat-2 SAR Interferometric Radar Altimeter (SIRAL)
Table 2. Comparison of GRACE GIS mass time series, 1 August 2003 to 1 August 2009. (Avg. ker.: averaging kernel)

\begin{tabular}{lccc}
\hline Centre technique & Trend & $\begin{array}{c}\text { Annual } \\
\text { amplitude }\end{array}$ & $\begin{array}{c}\text { Annual } \\
\text { phase } \\
\text { Gt }\end{array}$ \\
& & Gt & day of year \\
\hline GSFC v08 mascons & $-180 \pm 6$ & $167 \pm 21$ & $87 \pm 5$ \\
GSFC v08 avg. ker. & $-175 \pm 14$ & $158 \pm 49$ & $98 \pm 13$ \\
GFZ R04 avg. ker. & $-203 \pm 13$ & $153 \pm 45$ & $104 \pm 13$ \\
CSR R04 avg. ker. & $-222 \pm 14$ & $150 \pm 42$ & $100 \pm 14$ \\
Average \pm std dev. & $-195 \pm 22$ & $157 \pm 7$ & $97 \pm 7$ \\
& & & \\
\hline
\end{tabular}

instrument uses SAR techniques in the along-track direction and an interferometry mode (using two receiving antennae) across-track to locate much more precisely the position of the radar returns, allowing it to resolve more complex relief.

ICESat (http://ICESat.gsfc.nasa.gov/ICESat/) provided the first satellite laser altimeter observations of ice sheets. The loss of this satellite in 2009 prevented the valuable opportunity to fly concurrently with CryoSat-2, precluding acquisition of simultaneous radar and laser observations. However, the second generation of this laser altimeter, ICESat2 (http://ICESat.gsfC.nasa.gov/ICESat2/), is scheduled for launch in 2015. Improvements in design will mean dense across-track measurements of slope and sub-metre alongtrack sampling.

SAR imaging systems and the development of InSAR have provided vast amounts of information on ice surface features, elevation and motion. In recent years, the number of orbiting SAR systems has increased dramatically, adding to the long time series of data provided by the European Space Agency (ESA) and RADARSAT. Continuity of C-band systems will be provided with the launch of the ESA

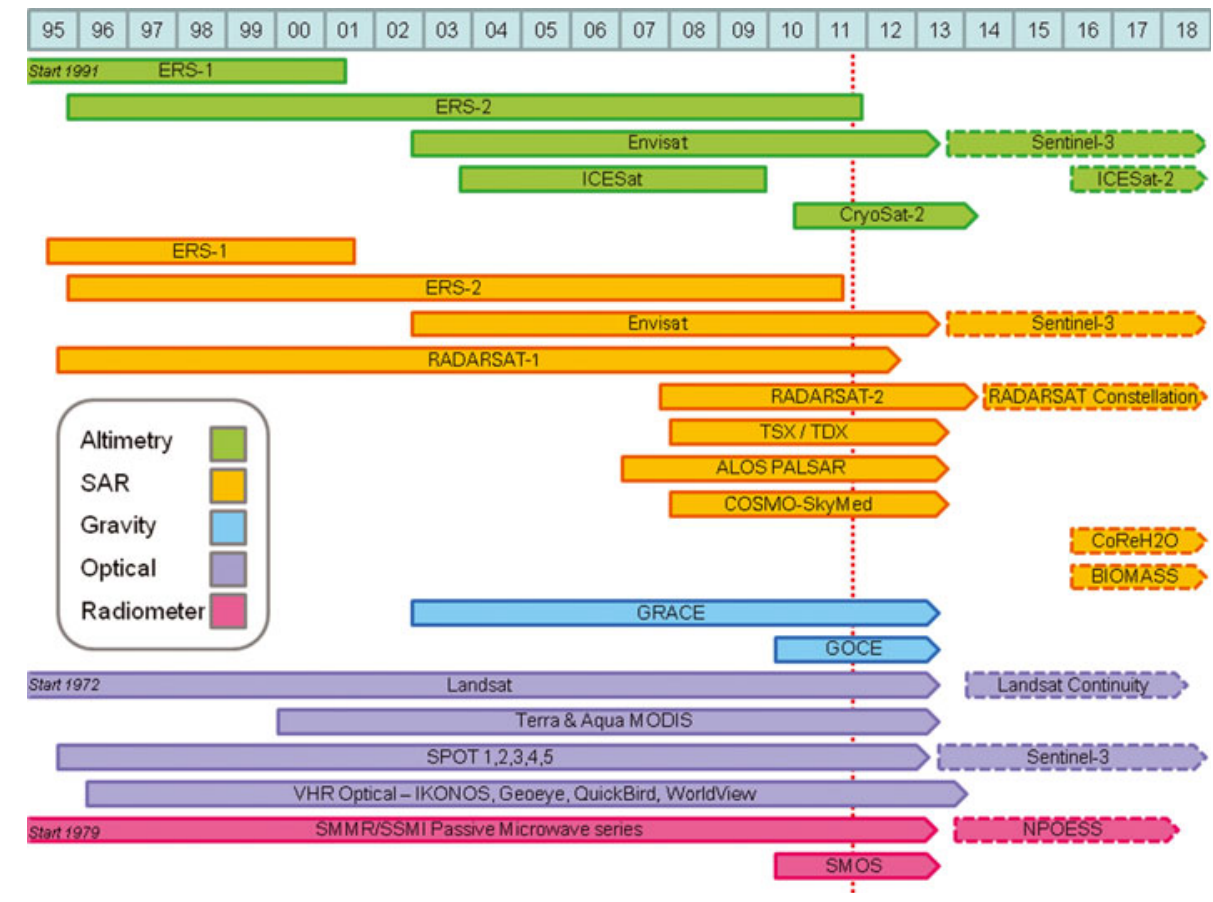

Fig. 12. Past, present and future remote-sensing satellites applicable to glaciology. Labels with dashed lines indicate missions that have not 
Sentinel-1 series (the first in the series will be launched in 2012, the second a few years later) and the RADARSAT Constellation (comprising three satellites due for launch beginning in 2014). A number of higher-frequency X-band SAR systems have also been launched recently including the Italian Cosmo-Skymed (Constellation of small Satellites for the Mediterranean basin Observation; http://www.cosmoskymed.it) and German TerraSAR systems (http://www.infoterra.de/terrasar-x), with TerraSAR partnering its twin satellite TandemX (http://www.infoterra.de/tandem-X-satellite) to deliver high-resolution interferometric elevation data. These new SAR systems all provide a range of acquisition modes, offering imagery with varying resolutions from $100 \mathrm{~m}$ down to $1 \mathrm{~m}$ in many cases. In addition, several of these SAR sensors have evolved from acquiring single polarization data to being fully polarimetric (transmitting and receiving in all combinations of both vertical and horizontal plane). This information can be used to derive much more information about the physical and scattering properties of the surface (e.g. on snow grain size, snow wetness and ice layering).

Satellite optical imaging systems have also provided observations of ice sheets and glaciers over a long period, in particular the Landsat series. Given technical problems with the current Landsat 7 sensor there are plans to update this series (http://ldcm.nasa.gov/), providing ongoing multispectral imagery at moderate resolution $(\sim 15 \mathrm{~m})$ with a launch in late 2012. As part of the Sentinel series, ESA also plan to launch a multispectral imaging system in 2012 which will provide continuity of the French Système Probatoire pour l'Observation de la Terre (SPOT) satellite data at resolutions of $\sim 10 \mathrm{~m}$. Much higher-resolution optical imagery is currently available from commercial satellites such as WorldView and IKONOS, acquiring data with submetre resolution. New and forthcoming high-resolution satellites will mean even greater availability of this type of imagery, offering extremely high detail of ice-sheet and glacier surface features.

A new concept under development is a satellite radar sounding system for measurement of ice-sheet thickness and internal structure. A candidate mission for the ESA Earth Explorer series (http://www.esa.int/esaLP/ESADQ0UHN6D_ LPfuturemis_0.html) called BIOMASS hopes to fly a P-band polarimetric SAR, with investigation of ice-sheet thickness and structure as a secondary objective.

Aside from development of new space hardware to observe the cryosphere, changes to data-access policies also have significant potential to affect the availability and use of remote-sensing data. Data access and sharing have been limited in the past by restrictive licence agreements, but recent policy changes by agencies such as ESA, and future plans for more open data policies from RADARSAT, point to a more widespread adoption of a free and open access to data similar to that employed in the United States. While this will never be the case for all satellite operators, such changes have significant implications for increased use of remote-sensing data, especially when viewed in parallel with new, faster access to online data services.

\section{CONCLUSIONS}

With progress in technology and a lengthening data archive, remote sensing for glaciology has moved beyond mapping of the cryosphere and on to monitoring change. In particular, three independent approaches have been developed to monitor trends in ice-sheet mass balance, based on remotely sensed measurements of glacier flow, surface elevation and the gravity field. We have focused on the latter two and have noted that advances in altimetry and gravimetry are improving our understanding of mass balance, in particular through increased spatial and temporal resolution of their change products. Perhaps most importantly, progress is being made in identifying the causes of change. This is due both to improvements in individual sensors and techniques and to synergies between remotely sensed data.

We have presented ICESat altimetry from Greenland that shows the distribution of ice loss which is concentrated on narrow, fast-flowing outlet glaciers on the southeast and northwest ice-sheet margins, and we are able to attribute this to glacier acceleration. We also find that while the ablation rate at a site in the northeast has changed little, dynamic losses in the northwest accelerated over the altimetry observation period, observations that support previous, independent SAR measurements of glacier flow that sampled snapshots of the time-varying glacier dynamic behaviour.

Over the same period, GRACE gravimetry detected a strongly negative interannual ice-sheet mass-balance trend $\left(-195 \mathrm{Gta}^{-1}\right)$, upon which is superimposed the seasonal cycle dominated by the surface mass-balance component of the GIS, now resolved in detail and with increased confidence. By combining the three data sources, we see where and how quickly rapid ice losses are occurring (marine-terminating outlet glaciers) and why (flow acceleration), to what extent each winter's snowfall balances summer melt, and the magnitude and trend of the ice sheet's overall net mass imbalance.

Gravimetry results from the GoA showed a similar interannual negative trend in mass balance, but with a high degree of spatial and temporal variability revealed by the high spatial $\left(2^{\circ}, \sim 200 \mathrm{~km}\right)$ and temporal (10 day) resolution now possible with GRACE data. Such resolution allows analysis of mass fluctuations in individual mountain ranges with particular melt and accumulation events. Improvements in the spatial resolution of altimetry (from the $2-3 \mathrm{~km}$ footprints of ERS/Envisat to the $65 \mathrm{~m}$ of ICESat) have allowed very detailed observations of individual glaciers. We have presented new results from Antarctic Peninsula ice-shelf tributary glaciers that complement previous, similarly highresolution optical and radar studies of glacier flow. Together, they show that when an ice shelf collapses, the lower reaches of tributary glaciers accelerate abruptly and the glacier starts to thin rapidly. This thinning effect then can propagate tens of kilometres inland over subsequent years, in qualitative agreement with modelling studies.

In summary, we have described advances in measuring glacier and ice-sheet change through remote sensing, progress that is important because it allows us to begin to focus on the attribution of change to the causes of change, and ultimately on the physical mechanisms by which the glaciers respond. Understanding of the physical mechanisms has struggled to keep pace with the supply of new remotely sensed information, though, and so estimates of future change, and in particular the near-future glacial sea-level contribution, still rely on projections from observations and not predictions from physical ice-sheet models. It is critical, therefore, that the observations continue and that satellite studies are designed to address the specific needs of glaciology. The next generation of new high-resolution altimeters, SAR and optical sensors aims to do just that. 


\section{REFERENCES}

Abshire, J.B. and 7 others. 2005. Geoscience Laser Altimeter System (GLAS) on the ICESat Mission: on-orbit measurement performance. Geophys. Res. Lett., 32(21), L21S02. (10.1029/ 2005GL024028.)

Arendt, A.A., S.B. Luthcke, C.F. Larsen, W. Abdalati, W.B. Krabill and M.J. Beedle. 2008. Validation of high-resolution GRACE mascon estimates of glacier mass changes in the St Elias Mountains, Alaska, USA, using aircraft laser altimetry. J. Glaciol., 54(188), 778-787.

Bøggild, C.E., N. Reeh and H. Oerter. 1994. Modelling ablation and mass-balance sensitivity to climate change of Storstrømmen, northeast Greenland. Global Planet. Change, 9(1-2), 79-90.

Doake, C.S.M., H.F.J. Corr, H. Rott, P. Skvarca and N.W. Young. 1998. Breakup and conditions for stability of the northern Larsen Ice Shelf, Antarctica. Nature, 391(6669), 778-780.

Ettema, J. and 6 others. 2009. Higher surface mass balance of the Greenland ice sheet revealed by high-resolution climate modelling. Geophys. Res. Lett., 36(12), L12501. (10.1029/ 2009GL038110.)

Gaposchkin, E.M. 2000. Geoid recovery using geophysical inverse theory applied to satellite to satellite tracking data. NASA Contract Rep. NAS5-99123.

Helsen, M.M. and 7 others. 2008. Elevation changes in Antarctica mainly determined by accumulation variability. Science, 320(5883), 1626-1629.

Holland, D.M., R.H. Thomas, B. de Young, M.H. Ribergaard and B. Lyberth. 2008. Acceleration of Jakobshavn Isbræ triggered by warm subsurface ocean waters. Nature Geosci., 1(10), 659-664.

Howat, I.M., I. Joughin, S. Tulaczyk and S. Gogineni. 2005. Rapid retreat and acceleration of Helheim Glacier, east Greenland. Geophys. Res. Lett., 32(22), L22502. (10.1029/2005GL024737.)

Howat, I.M., I.R. Joughin and T.A. Scambos. 2007. Rapid changes in ice discharge from Greenland outlet glaciers. Science, 315(5818), 1559-1561.

Howat, I.M., I. Joughin, M. Fahnestock, B.E. Smith and T. Scambos. 2008. Synchronous retreat and acceleration of southeast Greenland outlet glaciers 2000-2006: ice dynamics and coupling to climate. J. Glaciol., 54(187), 646-660.

Joughin, I., W. Abdalati and M.A. Fahnestock. 2004. Large fluctuations in speed on Greenland's Jakobshavn Isbræ glacier. Nature, 432(7017), 608-610.

Joughin, I., B.E. Smith, I.M. Howat, T. Scambos and T. Moon. 2010. Greenland flow variability from ice-sheet-wide velocity mapping. J. Glaciol., 56(197), 415-430.

Kahn, W.D., S.M. Klosko and W.T. Wells. 1982. Mean gravity anomalies from a combination of Apollo/ATS 6 and GEOS 3/ATS 6 SST tracking campaigns. J. Geophys. Res., 87(B4), 2904-2918.

Klees, R. and 6 others. 2008. The design of an optimal filter for monthly GRACE gravity models. Geophys. J. Int., 175(2), 417-432.

Luckman, A., T. Murray, R. de Lange and E. Hanna. 2006. Rapid and synchronous ice-dynamic changes in East Greenland. Geophys. Res. Lett., 33(3), L03503. (10.1029/2005GL025428.)

Luthcke, S.B., D.D. Rowlands, F.G. Lemoine, S.M. Klosko, D. Chinn and J.J. McCarthy. 2006a. Monthly spherical harmonic gravity field solutions determined from GRACE inter-satellite range-rate data alone. Geophys. Res. Lett., 33(2), L02402. (10.1029/ 2005GL024846.)

Luthcke, S.B. and 8 others. 2006b. Recent Greenland ice mass loss by drainage system from satellite gravity observations. Science, 314(5803), 1286-1289.

Luthcke, S.B., A.A. Arendt, D.D. Rowlands, J.J. McCarthy and C.F. Larsen. 2008. Recent glacier mass changes in the Gulf of Alaska region from GRACE mascon solutions. J. Glaciol., 54(188), 767-777.

Payne, A.J., A. Vieli, A. Shepherd, D.J. Wingham and E. Rignot. 2004. Recent dramatic thinning of largest West Antarctic ice stream triggered by oceans. Geophys. Res. Lett., 31(23), L23401. (10.1029/2004GL021284.)

Pritchard, H.D., R.J. Arthern, D.G. Vaughan and L.A. Edwards. 2009. Extensive dynamic thinning on the margins of the Greenland and Antarctic ice sheets. Nature, 461(7266), 971975.

Reeh, N. and 6 others. 2002. Glacier specific ablation rate derived by remote sensing measurements. Geophys. Res. Lett., 29(16), 10-11.

Reeh, N., J.J. Mohr, S.N. Madsen, H. Oerter and N.S. Gundestrup. 2003. Three-dimensional surface velocities of Storstrømmen glacier, Greenland, derived from radar interferometry and icesounding radar measurements. J. Glaciol., 49(165), 201-209.

Reigber, C. and 7 others. 2005. An Earth gravity field model complete to degree and order 150 from GRACE: EIGENGRACE02S. J. Geodyn., 39(1), 1-10.

Riffenburgh, B., ed. 2006. Encyclopedia of the Antarctic, Vol. 1. New York, Routledge.

Rignot, E. and P. Kanagaratnam. 2006. Changes in the velocity structure of the Greenland Ice Sheet. Science, 311(5673), 986990.

Rignot, E., S. Gogineni, I. Joughin and W. Krabill. 2001. Contribution to the glaciology of northern Greenland from satellite radar interferometry. J. Geophys. Res., 106(D24), 34,00734,019 .

Rignot, E., G. Casassa, P. Gogineni, W. Krabill, A. Rivera and R. Thomas. 2004. Accelerated ice discharge from the Antarctic Peninsula following the collapse of Larsen B ice shelf. Geophys. Res. Lett., 31(18), L18401. (10.1029/2004GL020697.)

Rignot, E., J.E. Box, E. Burgess and E. Hanna. 2008. Mass balance of the Greenland ice sheet from 1958 to 2007. Geophys. Res. Lett., 35(20), L20502. (10.1029/2008GL035417.)

Rott, H., W. Rack, P. Skvarca and H. De Angelis. 2002. Northern Larsen Ice Shelf, Antarctica: further retreat after collapse. Ann. Glaciol., 34, 277-282.

Rott, H., W. Rack and T. Nagler. 2007. Increased export of grounded ice after the collapse of Northern Larsen Ice Shelf, Antarctic Peninsula, observed by Envisat ASAR. In IGARSS '07, 27th International Geoscience and Remote Sensing Symposium, 23-27 July 2007, Barcelona, Spain. Proceedings, Vol. 3. Piscataway, NJ, Institute of Electrical and Electronics Engineers, 673-675.

Rowlands, D.D., R.D. Ray, D.S. Chinn and F.G. Lemoine. 2002. Short-arc analysis of intersatellite tracking data in a gravity mapping mission. J. Geod., 76(6-7), 307-316.

Rowlands, D.D. and 7 others. 2005. Resolving mass flux at high spatial and temporal resolution using GRACE intersatellite measurements. Geophys. Res. Lett., 32(4), L04310. (10.1029/ 2004GL021908.)

Rowlands, D.D. and 7 others. 2010. Global mass flux solutions from GRACE: a comparison of parameter estimation strategies mass concentrations versus Stokes coefficients. J. Geophys. Res., 115(B1), B01403. (10.1029/2009JB006546.)

Rummel, R. 1980. Geoid heights, geoid height differences, and mean gravity anomalies from 'low-low' satellite-to-satellite tracking - an error analysis. Bedford, MA, Hanscom Air Force Base. Air Force Geophysics Laboratory. (Contract F1962879-C-0027.)

Sabaka, T.J., D.D. Rowlands, S.B. Luthcke and J.-P. Boy. 2010. Improving global mass flux solutions from Gravity Recovery and Climate Experiment (GRACE) through forward modeling and continuous time correlation. J. Geophys. Res., 115(B11), B11403. (10.1029/2010JB007533.)

Scambos, T.A., C. Hulbe, M. Fahnestock and J. Bohlander. 2000. The link between climate warming and break-up of ice shelves in the Antarctic Peninsula. J. Glaciol., 46(154), 516-530.

Scambos, T., C. Hulbe and M. Fahnestock. 2003. Climate-induced ice shelf disintegration in the Antarctic Peninsula. In Domack, E.W., A. Burnett, A. Leventer, P. Conley, M. Kirby and R. Bindschadler, eds. Antarctic Peninsula climate variability: a historical 
and paleoenvironmental perspective. Washington, DC, American Geophysical Union, 79-92. (Antarctic Research Series 79.)

Scambos, T.A., J.A. Bohlander, C.A. Shuman and P. Skvarca. 2004. Glacier acceleration and thinning after ice shelf collapse in the Larsen B embayment, Antarctica. Geophys. Res. Lett., 31(18), L18402. (10.1029/2004GL020670.)

Scambos, T. and 7 others. 2009. Ice shelf disintegration by plate bending and hydro-fracture: satellite observations and model results of the 2008 Wilkins ice shelf break-ups. Earth Planet. Sci. Lett., 280(1-4), 51-60.

Schrama, E.J.O. and B. Wouters. 2011. Revisiting Greenland ice sheet mass loss ogbserved by GRACE. J. Geophys. Res., 116(B2), B02407. (10.1029/2009JB006847.)

Shepherd, A., D. Wingham and J.A. Mansley. 2002. Inland thinning of the Amundsen Sea sector, West Antarctica. Geophys. Res. Lett., 29(10), 1364. (10.1029/2001GL014183.)

Swenson, S. and J. Wahr. 2002. Methods for inferring regional surface-mass anomalies from Gravity Recovery and Climate Experiment (GRACE) measurements of time-variable gravity. J. Geophys. Res., 107(B9), 2193. (10.1029/2001JB000576.)

Tamisiea, M.E., E.W. Leuliette, J.L. Davis and J.X. Mitrovica. 2005. Constraining hydrological and cryospheric mass flux in southeastern Alaska using space-based gravity measurements. Geophys. Res. Lett., 32(20), L20501. (10.1029/2005GL023961.)
Tapley, B.D., S. Bettardpur, M. Watkins and C. Reigber. 2004. The gravity recovery and climate experiment: mission overview and early results. Geophys. Res. Lett., 31(6), L09607. (10.1029/ 2004GL019920.)

Thomas, R. and 6 others. 2008. A comparison of Greenland icesheet volume changes derived from altimetry measurements. J. Glaciol., 54(185), 203-212.

Velicogna, I. 2009. Increasing rates of ice mass loss from the Greenland and Antarctic ice sheets revealed by GRACE. Geophys. Res. Lett., 36(19), L19503. (10.1029/2009GL040222.)

Velicogna, I. and J. Wahr. 2005. Greenland mass balance from GRACE. Geophys. Res. Lett., 32(18), L18505. (10.1029/ 2005GL023955.)

Wingham, D.J., A. Shepherd, A. Muir and G.J. Marshall. 2006. Mass balance of the Antarctic ice sheet. Philos. Trans. R. Soc. London, Ser. A, 364(1844), 1627-1635.

Wingham, D.J., D.W. Wallis and A. Shepherd. 2009. Spatial and temporal evolution of Pine Island Glacier thinning, 1995-2006. Geophys. Res. Lett., 36(17), L17501. (10.1029/2009GL039126.)

Wouters, B., D. Chambers and E.J.O. Schrama. 2008. GRACE observes small-scale mass loss in Greenland. Geophys. Res. Lett., 35(2), L20501. (10.1029/2008GL034816.)

Zwally, H.J. 1987. Technology in the advancement of glaciology. J. Glaciol., Special Issue, 66-77. 